\title{
My Orange Is Bigger Than Your Apple: \\ U. S. and Japanese Executive Compensation
}

\author{
Abagail McWilliams \\ University of Illinois at Chicago \\ Samuel R. Gray \\ New Mexico State University \\ David D. Van Fleet \\ Arisona State University
}

\begin{abstract}
There appear to be large differences in the compensation of American and Japanese executives. Such statements suffer from a number of shortcomings, one of which is that compensation takes different forms in the U.S. and Japan. As a result, a classic error of comparing apples and oranges occurs. We use a broad definition of compensation and some preliminary data and find that the large differences may disappear when adjusted for the value of insider information.
\end{abstract}

\section{Background}

"The man who works for the gold in the job rather than for the money in the pay envelope, is the fellow who gets on." - Joseph French Johnson

While the above may be wisdom, when attention is directed to top executives it is almost always the money in the pay envelope that is of interest. Criticisms aimed at the compensation of corporate executives in the U.S. frequently make comparisons between the pay of U.S. and Japanese executives. For example, Business Week has reported that Japanese CEOs receive about one-fourth the compensation of comparable U.S. CEOs (Cover Story, 1993). And, Industry Week has pointed out that while Japanese executives earn about eleven times what a typical factory worker does; in the U.S. executives earn more than twenty-four times what the typical factory worker does (Verespej, 1992).

Such comparisons have been almost universally dependent upon anecdotal evidence because, unlike American firms, Japanese firms are not required by law to disclose the compensation of their executives. Despite constant attention of the popular press and a profusion of anecdotal evidence, the compensation of U.S. executives relative to Japanese executives has escaped the scrutiny of academic research. This is understandable given the lack of reliable information on Japanese compensation. Lacking hard evidence to the contrary, it is tempting for researchers to jump on the anecdotal bandwagon and denounce U.S. compensation practices. The typical conclusion drawn from the popular press and often supported by the academic community has been that, because U.S. executives receive several times the 
compensation of their Japanese counterparts, there is something inappropriate about the level of compensation in the U.S (Bron, 1992). Such conclusions are often followed by calls for government regulation or self reform of the compensation practices of U.S. firms (Brown, 1992).

The purpose of this paper is to present preliminary evidence to address the apparent large compensation difference noted above. The main hypothesis is that the apparent substantial difference between U.S. and Japanese executive compensation level may be due, in part, to differences in the manner in which executives in the different countries are compensated. That is, the popular press has been comparing oranges to apples. We propose using a broader definition of compensation -- income and wealth creation that results directly from the employment relationship -- to compare the compensation of U.S. and Japanese executives. This definition allows us to test for differences in more comparable measures of compensation.

\section{Determinants of Compensation}

The level of executive compensation depends on many factors. One factor is firm performance, which is typically estimated by looking at either stock price or accounting rates of return (Buchhottz, Young, \& Powell, 1998). Using stock prices, researchers have demonstrated that this relationship is very weak, especially for very large firms (Jensen \& Murphy, 1990). It was suggested that this is a result of political forces operating both in the public sector and inside firms. Using accounting rates of return, it was found that while executive pay is correlated to profits, compensation is primarily determined by the managerial labor market (Ciscel \& Carrol, 1980). Other factors that have been identified as determinants of the level of compensation include the industry in which the firm operates, the size of the firm, the growth rate of the firm, the tenure of the executive, and governance structures (Boyd, 1994; Deckop, 1988; Gomez-Mejia, Tosi, \& Hinken, 1987). To the extent that any of these factors varies significantly between firms in the U.S. and Japan, these differences could be contributing to observed differences in compensation levels (Kato, 1997).

There are also institutional and cultural differences that might lead to a disparity in compensation between Japanese and U.S. CEOs (Abowd \& Bognanno, 1995; Kato \& Hebner, 1997). One of these differences is that U.S. and Japanese executives do not bear the same level of compensation risk. Japanese executives are seldom fired even when company performance is extremely poor. For U.S. executives, on the other hand, firings have become a way of life. Therefore, because of the positive relationship between risk and return, we might expect that the pay of U. S. executives would be somewhat higher than that of Japanese executives. Another difference is that the labor market for managers is much less competitive in Japan than it is in the U.S (Kang \& Shivdasani, 1995). The Japanese culture rewards long term commitment and loyalty and places extreme limits on the opportunities that executives have to seek employment with a different firm. As a consequence, Japanese executives seldom leave their employers and join other firms. In the U. S., on the other hand, changing employers is relatively commonplace. Therefore, it can said that a relatively competitive labor market for managers exists in the U.S., while in Japan the labor market more closely resembles a monopsony (single buyer). We would expect that the market wage rate would be 
higher in the more competitive U.S. market than in the less competitive Japanese market. Finally, compensation levels might appear to differ because of differences in the manner in which executives are compensated.

There may be fundamental differences in the manner in which executives are compensated in Japan and the U.S. One difference concerns the cultural and legal implications of insider trading in the two countries. In the U.S. insider trading is illegal and the laws against it are vigorously enforced. Therefore, U.S. executives cannot receive any of their compensation through the value of insider information. In Japan sanctions against insider are generally not enforced and the cultural norm supports trading on insider information. Therefore, Japanese executives may receive some of their compensation through the value of insider information.

"Insider trading is simply not viewed as wrong" in Japan (Swan, 1990), although the practice has been technically illegal since the end of World War II (George, Standberry, \& Boss, 1990). The law on insider trading (as well as other securities regulation) was imposed by the Allied Occupation Headquarters (Matsui, 1991). The Japanese never bought into the regulation, however, and enforcement of insider trading laws has been virtually non-existent. Prior to the passage of reform legislation in 1988, there had been no criminal prosecution for insider trading (New Laws for Old, 1988). The reform legislation passed in 1988 also apparently had very little impact on the practice of insider trading. The first insider trading case to go to trial in Japan was decided in 1992, when a senior managing director of Macross Corporation was found guilty of trading on insider information. The director's punishment consisted of a fine of the equivalent of $\$ 4,144$ (Japanese Executive Found Guilty of Insider Trading, 1992). Because insider trading is deeply ingrained in the social and cultural fabric of Japanese life, enforcement and prosecution are unlikely (George, et al., 1990).

In addition, the regulatory and legal structures of Japan are ill suited to vigorous enforcement. The Securities Bureau of the Ministry of Finance (the equivalent of the U.S. Securities and Exchange Commission) has only 140 investigators, compared to over 2,000 for the SEC (George, et al., 1990). In addition, the Japanese Securities Bureau has no enforcement arm, leaving only the local police to implement the laws (Over to the Men in Uniform, 1990). In addition, civil suits or class action suits are hampered by the cultural norms. Japanese society emphasizes harmony; litigation is seen as a threat to this norm (Swan, 1990). In summary, according to The Economist, "Insider trading is as illegal in Tokyo as breaking the speed limit--and about as widespread." (Over to the Men in Uniform, 1990). 


\section{Defining and Measuring Compensation}

Differences in the cultural and legal implications of insider trading in Japan and the U.S. are central to the argument of this paper. This argument is that compensation should be defined as the income and wealth that an executive receives as a direct result of his/her employment relationship. Because Japanese executives apparently can reap income from trading on the information they receive as employees, the value of insider information constitutes a portion of the compensation of Japanese executives. This form of compensation is illegal and vigorously prosecuted in the United States. Hence, any comparisons of Japanese and U.S. executive compensation that do not consider the wealth effects of trading on inside information are erroneous and misleading.

The argument is as follows: Japanese executives are privy to inside information which has a positive economic value. This information can readily be converted into cash. Therefore, Japanese executives may be partially compensated in the form of information. To the extent that the value of insider information is not treated as compensation, Japanese executive compensation is understated.

U.S. executives, on the other hand, receive information which has no market value since they are not free to trade in their personal accounts based on this information. Therefore, U.S. executive compensation is not understated, but, in fact, properly reflects total compensation. Our hypothesis that U.S. executives do not receive any of their compensation in the form of inside information is consistent with the finding of Jensen and Murphy that there has been a "dramatic decline in the CEO stock ownership over the past 50 years..." (1990, p. 258). As it has become easier to detect insider trading and the enforcement of laws against such trading has become more vigilant, we would expect that CEOs would have traded stock ownership for higher salaries. Because of differences in insider trading laws, we would expect Japanese executives to receive some compensation in the form of information and U.S. executives to receive all of their compensation in more measurable (and visible) forms, such as salary, bonus, fringe benefits, stock, and stock options (Lavelle \& Jespersen, 2001 and 2002). This is consistent with the different cultures of the two countries as well. Japanese culture places a high value on harmony. Very large wage differentials might lead to disharmony. Therefore, we would expect that measurable (or visible) differences in wages would be kept as low as possible. The American cultural, on the other hand, places a high value on individuality and a lower value on harmony. Therefore, we would expect to see more effort to encourage individual success and less concern about the effects of wage differentials on harmony.

The argument outlined in this paper does not imply equality of compensation for Japanese and U.S. executives. It does imply, however, that previous reports of large differences in pay may be unwarranted. This research was designed to analyze the differences in compensation using our broader definition -- income and wealth creation that results directly from the employment relationship. Therefore, we compare compensation after adjusting for the value of insider information. The hypothesis to be tested is: 
$\mathrm{H}$ : After adjusting for the value of insider trading, there is no significant difference between the compensation of Japanese and U.S. CEOs.

To test this hypothesis directly we would need compensation data (including the value of inside information) for Japanese CEOs. The determination of the monetary value of insider information to a given Japanese executive represented a formidable challenge to the present research, since no methodology exists for its estimation. The valuation process was further complicated by the fact that data were not available on the magnitude of insider trading activity by these Japanese executives, although anecdotal evidence suggests that the practice is pervasive. Data were available, however, that allowed us to estimate the value that insider trading would have to a U.S. executive, if the practice were legal in this country. The logic of the methodology for adjusting the value of compensation for insider trading is outlined below.

Let $\mathbf{U}=$ the reported (unadjusted) salary of a $\mathbf{U}$. S. executive and $\mathbf{J}=$ the reported salary of a Japanese executive in comparable size firms. Consider what would happen if insider trading laws were abandoned in the U. S., making U. S. executives free to trade in their own accounts using information that was not available to the market. The value of the U. S. executive's inside information would immediately increase by $\Phi$. The rational executive, then, would be just as well off by negotiating a new salary of $\mathbf{U}-\Phi$. The executive would then receive part of his or her compensation in information rather than cash and stock-related bonuses.

We would expect the following relationship if there were no substantive differences in compensation in the two countries: $\mathbf{J}=\mathbf{U}-\Phi$. This implies that, in the absence of differences in insider trading laws, there would be equality of pay in Japan and the U.S. If one could calculate $\Phi$, then, one could make comparisons between $\mathbf{J}$ and $\mathbf{U}$, Japanese and U.S. executive compensation, that are closer to comparing oranges to oranges or apples to apples.

To conduct our test we first estimated the value of inside information for the U.S. CEOs. Next, we subtracted this value from the reported compensation figures. This gave us a dollar value for $\mathbf{U}-\Phi$. We then compared $\mathbf{U}-\Phi$ to $\mathbf{J}$ to determine if there was any significant difference.

\section{Data}

In order to assure comparability of data, we had to use some that are a bit outdated. Clearly the validity of our results depends upon obtaining and analyzing a more current set of data. Because we did use older data, we have labeled our results as "preliminary."

Data on Japanese executives' compensation, for 1991, were obtained from the Business Week article, "What Do Japanese CEOs Really Make?" (Cover Story, 1993). These data were compiled for the CEOs of the 50 largest firms in Japan by the consulting firm of Towers and Perrin. Towers and Perrin got its information on income 
from public tax information. Because the tax information was not broken down by source of income, it was possible that reported income included such items as capital gains on personal property. Therefore, Towers and Perrin used information from 5 years of tax records to estimate the employment income to the Japanese CEOs. While not perfect, this is the best data source available to date. The 50th observation had to be dropped because complete compensation figures were not available for that executive. The final data set, therefore, consisted of the cash compensation of the CEOs of the largest 49 Japanese firms.

The compensation data on the CEOs of the 49 largest U.S. firms, for 1991, were also obtained from Business Week (Byrne, 1992). These compensation data consisted of salary, cash bonus, and the value of stock grants and stock options and were compiled from the firms' proxy statements.

\section{Method}

We estimated $\Phi$ using conventional event study technique (Fama, Fisher, \& Roll, 1969). This technique is widely used and accepted in accounting and finance as a way to determine the impact of some "event" on the value of a firm. It is generally accepted that some events, such as the announcement of a merger, will generate an abnormal return for a firm's stock on the days surrounding the event. (This is the type of information that insider-trading laws prevent executives from using to their personal advantage.) If the abnormal return per share is multiplied by the number of shares, the result is the total change in the value of the firm attributable to the event. Because it may take more than one day for the stock price to adjust to new information, it is typical to sum the abnormal returns over a few trading days, to allow for full adjustment of the stock price to the announcement. The number of days over which the abnormal returns are accumulated is known as the event "window."

This technique allowed us to estimate the affect that announcements such as an impending merger or unexpected earnings had on the stock price of the 49 largest U. S. corporations in 1991. To use this technique, one first estimates the return that a given stock will have, relative to the market return, for any one day period. This is the firm's expected daily return. The actual return for any day can then be compared to the expected. Any difference is considered to be an abnormal return. For this study we use five trading days (a commonly used period) as our window for estimating the total abnormal return. These five days included the day of the announcement, two days following the announcement and two days preceding the announcement. Two days preceding the announcement were included, because information about an announcement is often "leaked" to the market. Two days following the event were included to give time for the market to fully adjust.

The event window we used, then, began 2 days prior to an announcement and ended 2 days after an announcement in The Wall Street Journal. This short event window was chosen to permit a conservative estimate of the value of insider information. The accumulated abnormal returns we calculated represent the gains that the CEO could have made on each share of stock for a trade executed two days prior to an announcement and liquidated two days after an announcement. For each of the 49 
U.S. firms, we calculated the abnormal return for each event and summed all of these for the year. This calculation yielded the total value of insider information per share of stock for each firm for the 1991 calendar year.

The value of insider information to the CEOs was calculated by using the number of shares of stock that the CEOs owned, as recorded in the firms' proxy statements, as follows. We multiplied the per share total value of insider information (the sum of the abnormal returns) for the year by $1 / 2$ the number of shares of stock that the executive owned. Only half the executives' stock ownership was used in the evaluation since this represents the standard margin requirement of U.S. brokerage firms. Thus, this estimation method is very conservative as it ignores other forms of wealth that the executive may have had at his or her disposal to use for trading.

\section{Results}

The reported (unadjusted) compensation of CEOs in the top 49 Japanese and American firms are reported in Table 1. These results are consistent with prior reports that U.S. executives earn several times as much as their Japanese counterparts. We found that the mean for U.S. CEO compensation was approximately three times the mean for Japanese CEO compensation. In addition, a difference of means $t$-test and a nonparametric median difference test indicate that these differences are statistically significant.

\section{TABLE 1}

COMPARISON OF UNADJUSTED EXECUTIVE COMPENSATION IN TOP 49 FIRMS IN JAPAN AND THE UNITED STATES (U.S. DOLLARS)

\begin{tabular}{|c|c|c|}
\hline & Japan & U.S. \\
\hline Mean Unadjusted Compensation & $\$ 983,531$ & $\$ 2,802,306$ \\
\hline Median Unadjusted Compensation & $\$ 630,000$ & $\$ 993,523$ \\
\hline Standard Deviation & $1,150,277$ & $2,453,270$ \\
\hline $\mathrm{N}$ & 49 & 49 \\
\hline t-statistic, mean difference test & & \\
\hline$\chi$-square, median difference test & & \\
\hline
\end{tabular}

The results shown in Table 2 represent a comparison of compensation of Japanese and U.S. executives after adjustments were made for the value of insider information, as outlined above. As indicated in the table, when adjustments were made for the value of insider information, the differences between CEO compensation in the top 49 firms in Japan and the U.S. are not statistically significant.

\section{TABLE 2}




\section{EXECUTIVE COMPENSATION IN THE TOP 49 FIRMS IN JAPAN AND THE UNITED STATES (U.S. DOLLARS) ADJUSTED FOR VALUE OF INSIDER INFORMATION.}

\begin{tabular}{|c|c|c|c|}
\hline & Japan & & U.S. \\
\hline Mean Adjusted Compensation & $\$ 983,531$ & & $\$ 356,743$ \\
\hline Median Adjusted Compensation & $\$ 630,000$ & & $\$ 1,293,434$ \\
\hline Standard Deviation & $1,150,277$ & & $7,196,654$ \\
\hline $\mathrm{n}$ & 49 & & 49 \\
\hline t-statistic, mean difference test & & 0.60 & \\
\hline$\chi$-square, median difference test & & $9.18^{* *}$ & \\
\hline
\end{tabular}

In order to investigate the possibility that some outliers might be driving these results, U.S. executives with extremely large stock holdings and/or unusually large values for insider information were dropped from the analysis. The results of the analysis after this adjustment was made are essentially the same as those reported in Table 2. While the differences in compensation are not statistically significant, the median U.S. compensation is higher than the median Japanese compensation (the median difference test approaches significance at the 0.10 level). Because some of the factors that are thought to determine the level of compensation may vary between the U.S. and Japan, we also conducted an analysis that controlled for some of these factors. We report the results of this analysis in Appendix A

\section{Discussion}

Periodically, politicians and interest groups suggest that the compensation of U.S. executives should be regulated, because it is "too high" (Conyon \& Peck, 1998; Colvin \& Lose, 1992). This position is often supported by arguing that U.S. executives must be overpaid, because they are paid much more than the executives of comparable Japanese firms. Although there is widespread belief in this comparison, there is scant empirical evidence to support it (Taft \& Singh, 2003; Kaplan, 1994; Kato, 1997). Most such claims are supported by anecdotal evidence that ignores the differences in compensation laws and customs in the two countries, and does not control for differences in such things as firm size, profit ratio, and growth rate. This research was undertaken so that we might inject some objective evidence, albeit preliminary, into this debate. With that in mind, we provide an examination of differences in the level and form of compensation between U.S. and Japanese executives.

First, we discussed the determinants of compensation level and ways in which these might vary across countries. Some of the determinants include: 1) firm performance, 2) growth rate of the firm, 3) firm size, 4) industry in which the firm competes, and 5) governance structures. It is possible that the link between compensation and any of these variables may vary across countries because of cultural and institutional differences. Institutional differences that were discussed include the employment risk borne by the executives and the efficiency of the managerial labor markets in the two 
countries. Finally, we discussed differences in cultural norms and the enforcement of laws pertaining to insider trading.

We concluded that differences in the treatment of insider trading could be expected to result in Japanese executives receiving some of their compensation in the form of (valuable) information and U.S. executives receiving compensation only in more easily measurable (i.e., visible) forms, such as salary, bonus, fringe benefits, stock, and stock options. We are not offering this as evidence that Japanese executives necessarily trade on inside information. We are, instead, demonstrating that, to the extent that American executives cannot trade on inside information, they are more likely to be compensated in more traditional ways.

Based on our conclusion that the way in which executives are compensated might differ across these cultures, we examined the compensation of the CEOs of the 49 largest Japanese and U.S. firms. We found that, using standard measures of compensation, the U.S. CEOs were paid about three times as much as the Japanese CEOs. However, after controlling for the value of inside information, we found that there was no significant difference in compensation. This demonstrates that simply comparing the mean reported compensation for CEOs between countries may be misleading. It may be equivalent to comparing oranges to apples.

Our results suggest that the apparent large difference between the compensation of Japanese and U.S. CEOs may shrink when the concept of compensation is expanded to include the value of information received as a consequence of the executives' position with the firm. Any residual differences are understandable as resulting from differences in other factors, in particular institutional factors such as the difference in employment risk between the two countries. Most importantly, this study points out that calls for regulating the compensation of U.S. executives based on a comparison between U.S. and Japanese executives are clearly misguided, because a fair comparison cannot be made based on the widely reported "evidence."

\section{Appendix A}

Because some of the factors that are thought to determine the level of compensation may vary between the U.S. and Japan, we also conducted an analysis that controlled for some of these factors. This was accomplished by running three separate regressions in which we regressed 1) unadjusted pay, 2) adjusted pay, and 3) adjusted pay with outliers dropped, on variables known to covary with compensation. Included were the logarithm of firm size (as measured by sales in dollars), firm performance (using return on sales as a proxy), and industry growth rate. These data were obtained from the Compact Disclosure Worldscope Database. In these regressions, we also included a dummy variable defined as one if the executive was from a U.S. firm, zero is from a Japanese firm. The results are displayed in Table 3.

\section{TABLE 3 \\ COMPENSATION REGRESSED ON LOG OF SALES, RETURN ON SALES, GROWTH RATE, AND DUMMY VARIABLE (T-STATISTICS IN PARENTHESES)}




\begin{tabular}{lccc}
\hline \hline & 1. & 2. & 3. \\
& Unadjusted Pay & Adjusted Pay & $\begin{array}{c}\text { Adjusted Pay } \\
\text { with } \\
\text { Outliers Dropped }\end{array}$ \\
\hline & & & \\
Intercept & & & -11907388 \\
Dummy variable & $-12089545^{* * *}$ & -7840565 & $(-1.05)$ \\
& $(-2.76)$ & $(-0.565)$ & 500445 \\
Log of Sales & $2001225^{* * *}$ & -721512 & $(0.804)$ \\
Return on Sales & $(5.84)$ & $(-0.664)$ & 115622 \\
& $433182^{* *}$ & 943756 & $(1.442)$ \\
Growth Rate & $(2.33)$ & $(0.696)$ & $(3.55)$ \\
& $185769^{* * *}$ & 115133 & 37010 \\
$\mathrm{~N}$ & $(5.08)$ & $(-.296)$ & $(0.67)$ \\
$\mathrm{R}^{2}$ & $51379^{*}$ & -30736 & 96 \\
${ }^{*} \mathrm{p}<0.1,{ }^{* *} \mathrm{p}<0.05,{ }^{* * *} \mathrm{p}<0.001$ & $(1.67)$ & $(-0.316)$ & .140 \\
\hline
\end{tabular}

The dummy variable was added to test for a significant difference between U.S. and Japanese executives. As shown in Table 3, the coefficient on the dummy variable is significant only when the dependent variable is Unadjusted (reported) Pay. Once adjustments are made to account for the value of insider information, the results indicate a statistically insignificant difference between the Japanese and U.S. executives. This supports our hypothesis that, when adjustments are made for the value of insider information, there is no significant difference in the compensation of U.S. and Japanese CEOs.

It is also worth noting that the regression results show that the difference in the mean unadjusted compensation from the regression was approximately the same as the difference in the mean unadjusted compensation that was reported in Table 1. This shows that controlling for firm size, profit rate, and growth rate did not significantly affect the relative compensation levels. Therefore, there is no evidence that the impact of these factors on compensation varies across the two countries.

\section{References}

Abowd, J. \& Bognanno, M. (1995). International differences in executive and managerial compensation. In R. Freeman \& L. Katz (Eds.), Differences and Changes in Wage Structures (67-103). Chicago, IL: The University of Chicago Press.

Boyd, D. (1994). Board control and CEO compensation. Strategic Management Journal, 15, 335-344. 
Bremner, B. (1999, April 19). The stock-option option comes to Japan. BusinessWeek Online, 1-3.

Brown, D. (1992). Can we put the brakes on CEO pay? Management Review, May, 10-15.

Buchholtz, A., Young, M., \& Powell, G. (1998). Are board members pawns or watchdogs? The link between CEO pay and firm performance. Group \& Organization Management, 23 (1), 6-26.

Byrne, J.A. (1992). What, Me overpaid? CEO's fight back. Business Week, May 4, 142-143.

Ciscel, D., \& Carroll, T. (1980). The determinants of executive salaries: An econometric survey. Review of Economics and Statistics, 62, 7-13.

Colvin, G., \& Losee, S. (1992, April 6). How to pay the CEO right. Fortune, 125 (7), 6068.

Conyon, M. \& Peck, S.. (1998). Board control, remuneration committees, and top management compensation. Academy of Management Journal, 41 (2), 146-157.

Cover Story. (1993). Business Week, April 26, 56-64.

Deckop, J. (1988). Determinants of chief executive officer compensation. Industrial and Labor Relations Review, 41, 215-226.

Fama, E., Fisher, L., Jensen, M., \& Roll, R. (1969). The adjustment of stock prices to new information. International Economic Review, 10, 1-21.

George, B., Stanberry, K., \& Boss, M. (1990). New steps to prohibit insider trading in Japan: A serious commitment or simply 'saving face.' Asian Thought and Society, 15, 227-235.

Gomez-Mejia, L., Tosi, H, \& Hinken, T. (1987). Managerial control, performance, and executive compensation. Academy of Management Journal, 1987, 51-70.

Japanese executive found guilty of insider trading. (1992). Wall Street Journal, September 29, A11.

Jensen, M., \& Murphy, K. (1990). Performance pay and top-management incentives. Journal of Political Economy, 98,. 225-264.

Kang, J., \& Shivdasani, A. (1995). Firm performance, corporate governance, and top executive turnover in Japan. Journal of Financial Economics, 38, 29-58.

Kaplan, S. (1994). Top executive rewards and firm performance: A comparison of Japan and the United States. Journal of Political Economy, 102 (3), 510-546. 
Kato, T. (1997). Chief executive compensation and corporate groups in Japan - New Evidence from Micro Data. International Journal of Industrial Organization, 15(4), 455467.

Kato, T., \& Hebner, K.J. (1997). Insider trading and executive compensation: Evidence from the U.S. and Japan. International Review of Ecnomics and Finance, 6(3), 223237.

Lavelle, L., \& Jespersen, F. (2001, April 16). Executive pay. BusinessWeek Online, 16.

Lavelle, L., \& Jespersen, F. (2002, April 15). Executive pay: Special report. BusinessWeek Online, 80-86.

Matsui, I. (1991). The regulation of insider trading in japan--Comparing with the American Law. Comparative Law, 8, 83-97.

New laws for old. (1988). The Economist, October 1, 92.

Over to the men in uniform. (1990). The Economist, May 19, 91.

Reingold, J., \& Jespersen, F. (2000, April 17). Executive pay. BusinessWeek Online, 1-8.

Reingold, J., \& Grover, R. (1999, April 19). Special Report: Executive pay. BusinessWeek Online, 1-10.

Swan, W. (1990). The 1988 Japanese insider trading amendments: Will Japan see results from these tougher laws? University of Pennsylvania Journal of International Business Law, 12, 275-302.

Taft, D., \& Singh, G. (2003). Executive compensation: A comparison of the United States and Japan. Compensation and Benefits Review, 35(3), 68-78.

Verespej, M. (1992). Pay-for-skills: its time has come. Industry Week, June 15, 22-30. 